\title{
The Metallurgy of Some Carat Gold Jewellery Alloys
}

PART I - COLOURED GOLD ALLOYS

\author{
Allen S. McDonald and George H. Sistare \\ Handy \& Harman, Fairfield, Connecticut, U.S.A.
}

\begin{abstract}
The classification of gold alloys in terms of caratage and colour provides no guidance as to the properties and working characteristics of the many carat gold alloys used in jewellery fabrication. Logical relationships do exist, however, between the composition, metallurgical structure and properties of such alloys, and these emerge from a study of the phase diagrams of the alloy systems involved. Part I of this review deals with coloured gold alloys. Part II will discuss their nickel containing counterparts and will appear in the next issue of Gold Bulletin.
\end{abstract}

Most carat gold for jewellery falls into one or other of two major categories, the coloured gold alloys based on the gold-silver-copper or the gold-silvercopper-zinc system and the white gold alloys.

Although many coloured gold alloys contain zinc (from less than 1 to about 15 weight per cent), it is valid to introduce this group in terms of the goldsilver-copper ternary system, from which all of the alloys inherit certain fundamental metallurgical characteristics. After establishing these, the effects of zinc will be introduced, and it will then be seen that in the amounts used this element does not change these characteristics in kind but rather interacts to modify them in a regular and symmetrical way.

Figure 1 presents the gold-copper, copper-silver and silver-gold binary phase diagrams (1). The ternary phase diagram can be established by progressively adding gold to the copper-silver system. One might expect a liquidus valley to extend from the coppersilver eutectic point at $780^{\circ} \mathrm{C}$ to the gold-copper liquidus minimum at $911^{\circ} \mathrm{C}$. This valley exists and is shown in Figure 2. One might also expect the solid state immiscibility field in the copper-silver system to intrude into the ternary diagram to a considerable extent. Indeed it does, shrinking laterally and vertically, as compositions approach the gold corner. This is illustrated in Figure 3, where the solid state isothermal boundaries of the immiscibility field have been projected onto the room temperature plane. The existence of this immiscibility field is by far the most important factor in determining the basic metallurgical characteristics of the coloured jewellery gold alloys.
Three quasi-binary vertical sections of the ternary diagram at constant gold contents characteristic of jewellery alloys (10, 14 and 18 carat) are schematically represented in Figure 4 where the parameter used on the abscissa is defined as:

$$
\mathrm{Ag}^{\prime}=\frac{\mathrm{Ag} \text { wt. } \%}{\mathrm{Ag} \mathrm{wt.} \%+\mathrm{Cu} \text { wt. } \%} \times 100 \quad \text { (per cent) }
$$

Gold-silver-copper and gold-silver-copper-zincalloys can be logically classified and discussed in terms of two parameters, namely the caratage or gold content and Ag'.

Given constant gold content sections of the ternary diagram, for example the 14 carat section in Figure 4, the concept of three 'types' of alloy based on the immiscibility gap and defined by values of $\mathrm{Ag}^{\prime}$ can be introduced.

Type I where $\mathrm{Ag}^{\prime}$ ranges from 0 to about 10 per cent or from about 90 to 100 per cent. These alloys exist primarily as homogeneous solid solutions at all temperatures below the melting point. Alloys of this type are soft in the annealed condition and are not age-hardenable.

Type II where $\mathrm{Ag}^{\prime}$ is in the range from about 10 to 25 per cent or 75 to 90 per cent. These alloys will exist as homogeneous solid solutions at temperatures above the immiscibility gap, but if slowly cooled to equilibrium at room temperature $\propto_{(A g-A u)}$ will precipitate in copper-rich alloys and $\alpha_{(\mathrm{Cu}-\mathrm{Au})}$ in silverrich alloys. Type II alloys are moderately soft in the annealed condition but are age-hardenable by heat treatment. 
GOLD-COPPER

GOLD ATOMIC PER CEN
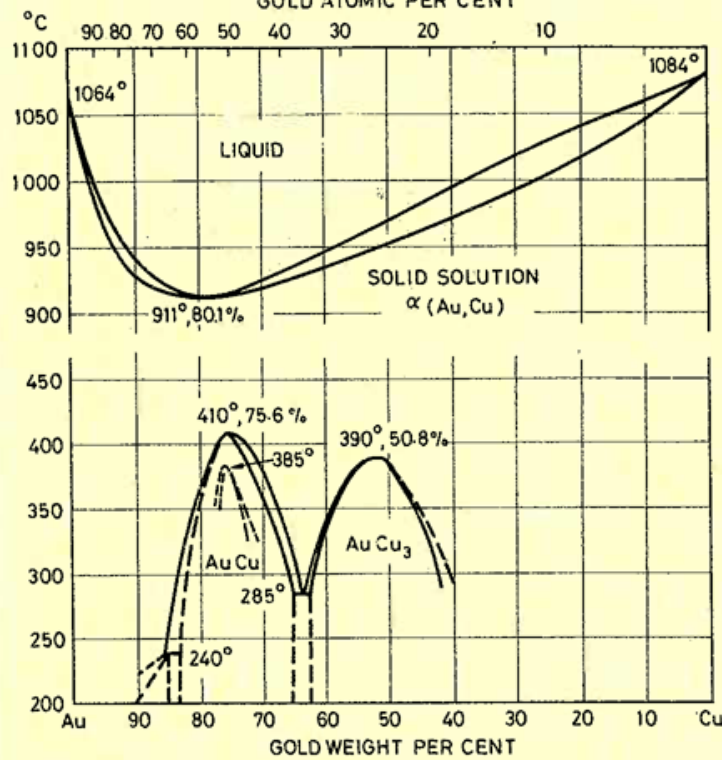

Fig. 1 Gold-copper, copper-silver and silver-gold binary phase diagrams. On the gold-copper diagram, note the minimum liquidus temperature and the existence of two ordered phases, $\mathrm{AuCu}$ and $\mathrm{AuCu}_{3}$. The copper-silver diagram shows that due to the eutectic decomposition of the homogeneous liquid phase into copper-rich and silver-rich phases, binary alloys are two-phase in the solid state except when either of copper or silver is present in a very small quantity only. Silver-gold binary alloys are single phase at all concentrations. After (1)

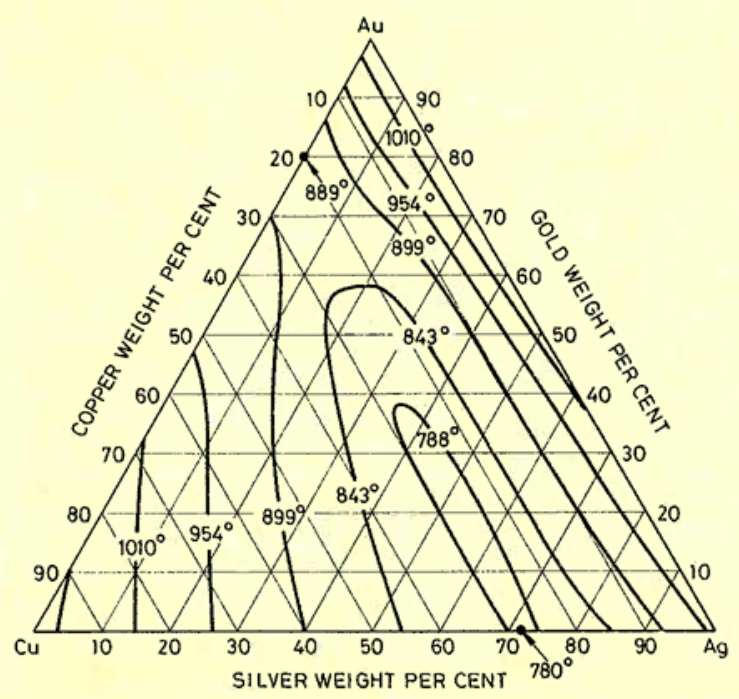

Fig. 2 Projection on the room temperature plane of the gold-silver-copper ternary phase diagram of some isotherms on the liquidus surface. A liquidus valley extends from the silvesicosper eutectic point to the goldcopper liquidus minimum. After (1)
COPPER - SILVER

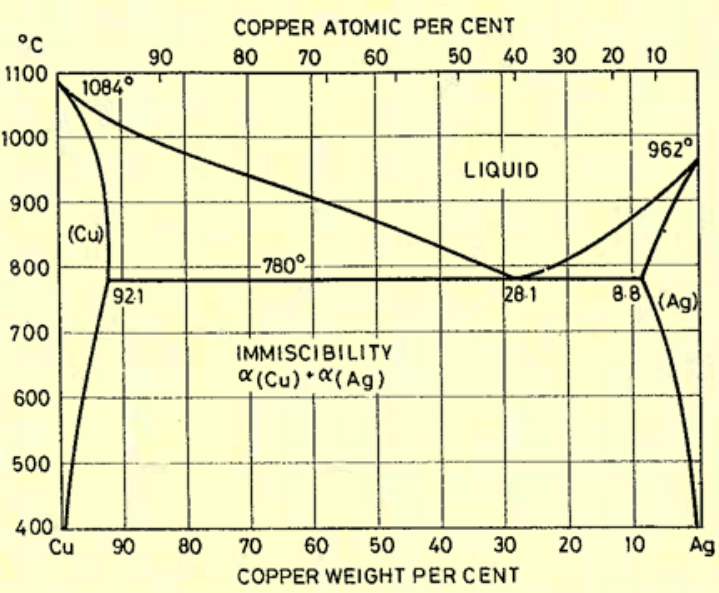

SILVER - GOLD
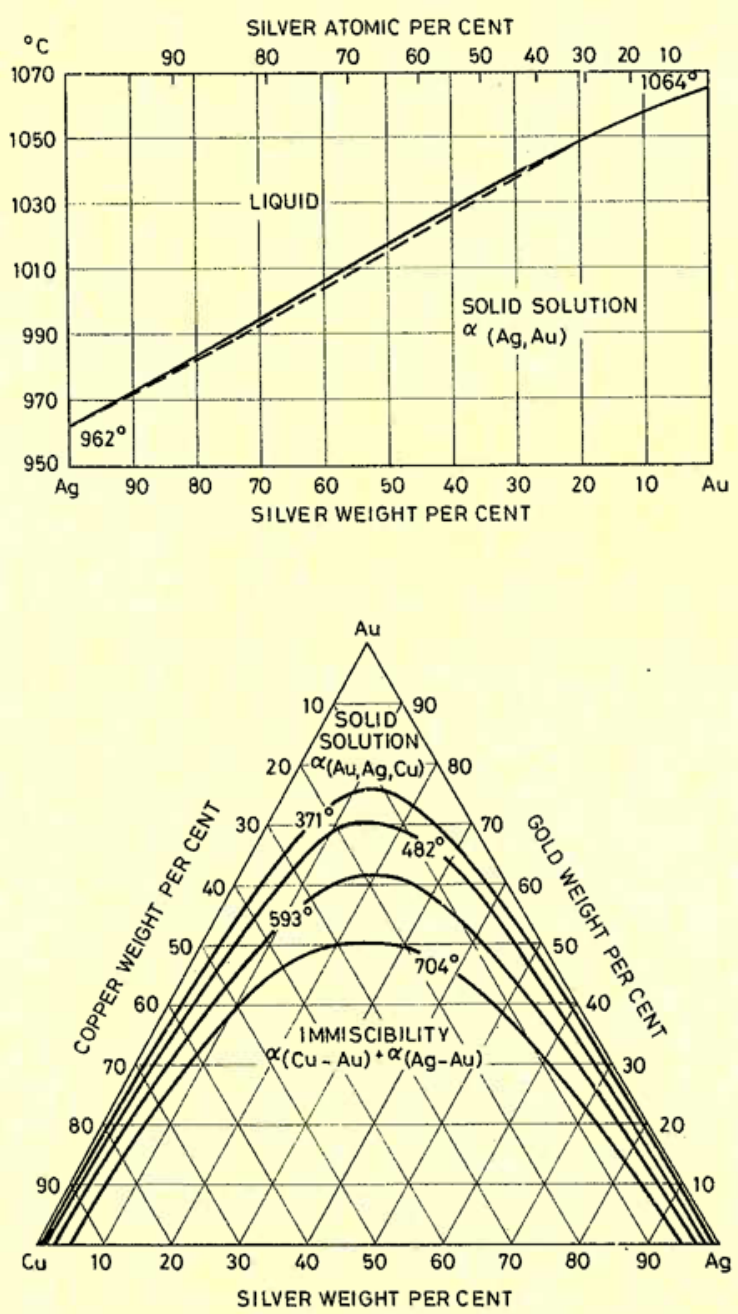

Fig. 3 Projection on the room temperature plane of the gold-silver-copper ternary phase diagram of some isothermal solid state boundaries of the immiscibility field. After (1) 

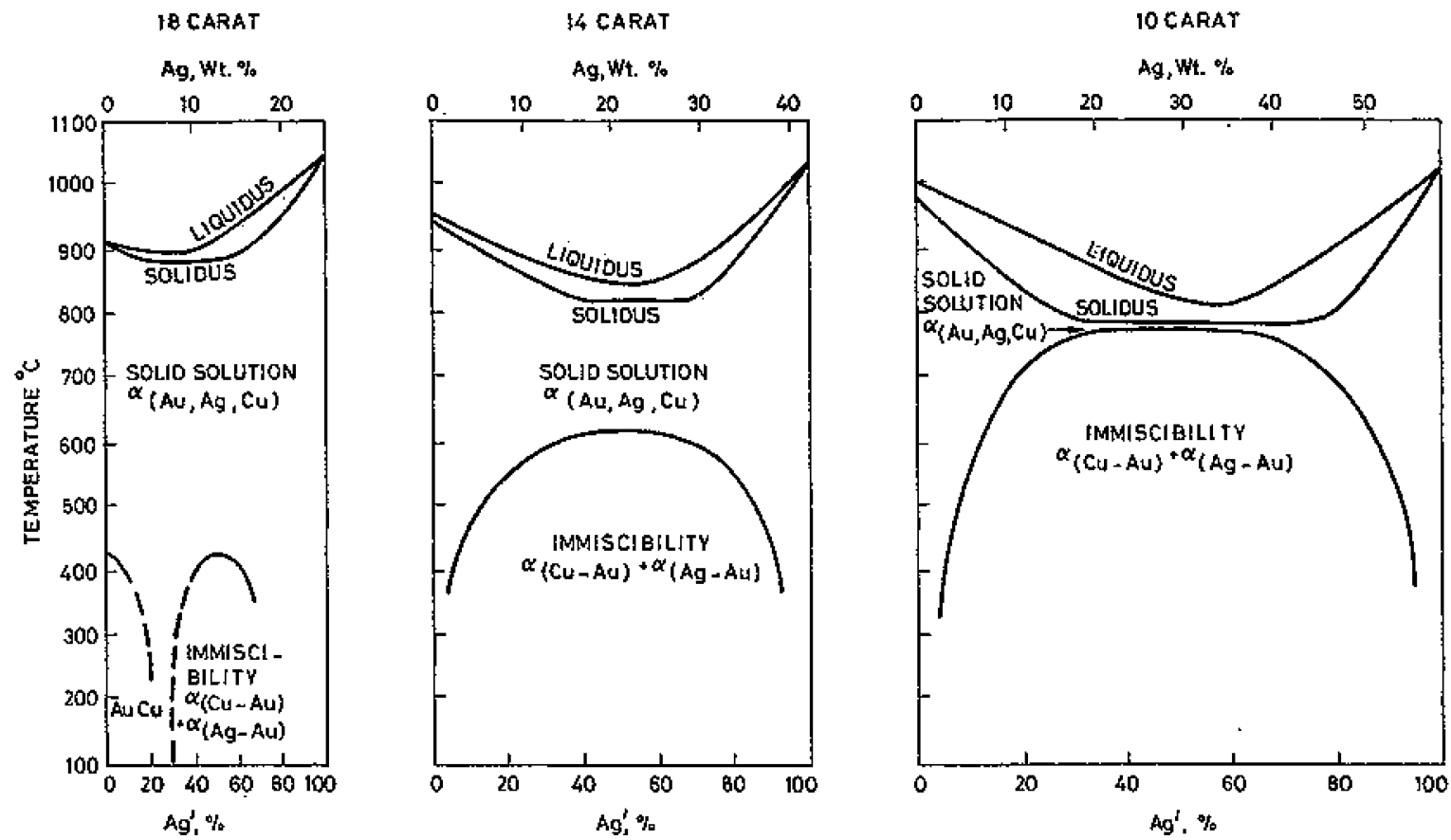

Fig. 4 Sehematic quasi-binary sections at constant caratage of the gold-silver-copper ternary phase diagram. The parrameter $\mathrm{Ag}^{\text {i }}$ is defined in the lext

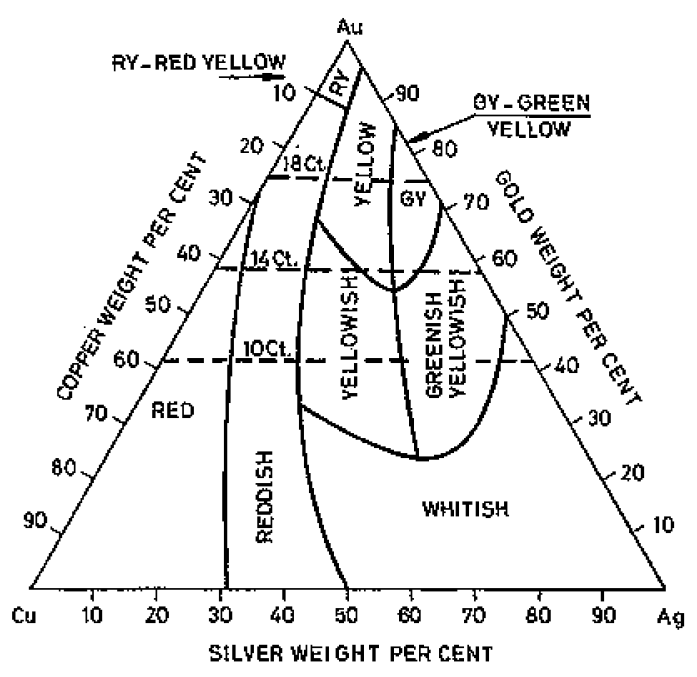

Fig. 5 Relationship between the colour and composition of gold-silver-copper alloys. After (2)

Type III where $\mathrm{Ag}^{\prime}$ is in the range from about 25 to 75 per cent. These alloys are homogeneous solid solutions at temperatures above the immiscibility gap; but if slowly cooled to equilibrium at room temperature they decompose into both $\alpha_{(A-A)}$ and $\alpha_{i C u A u)}$. Alloys of this type are hard in the annealed condition. They harden markedly during air cooling and are difficult to quench. Type III afloys are age-hatdenable.

In the jewellery industry, alloys are usually classified in terms of caratage and colour rather than of metallurgical properties. The hue of gold-silver. copper alloys could be expected to range from 'copper-red' near the copper-rich corner, to 'goldyellow' near the gold-rich corner, to 'silver-white' near the silver-rich corner. A more precise delineation (2) of the actual colour fields is illustrated in Figure 5 .

It will be noted in Figure 5 that 'copper-red' dominates not only the copper-rich comer but most of the copper-and gold-rich side of the diagram. Alloys in these red and reddish areas can be, and are, made yellowish by an addition of zinc.

The effect of zinc on the concept of alloy types as defined above, will be understood if it is borne in mind that the addition of this element tends to reduce (3) the volume of solid state immiscibility in the ternary phase diagram.

The small amounts of zinc (about 0.5 per cent or less) added as a deoxidizer in 10 and 14 carat alloys have no significant effect on the metallurgical characteristics under discussion. Larger additions (up to about 15 weight per cent) are, however, used to change the red colour of low and middle caratage copper-rich alloys to reddish yellow or dark yellow. These soften the alloys in both the annealed and precipitation hardened state. This is a consequence of the narrowing and reduction in height of the two phase area on each of the constant gold content sections of the ternary diagram shown in Figure 4.

These general concepts will aid a survey of some commercial alloys. For this purpose, the reader will 
find it useful to imagine the metallurgical concept of alloy types as a grid that may be superimposed on the colour diagram of Figure 5. Thus the jeweller's classification of alloys based on caratage and colour can be translated into the present metallurgical classification based on caratage and $\mathrm{Ag}^{\prime}$ values.

\section{Carat Coloured Alloys}

A survey of commercial gold alloys will best begin with alloys of intermediate caratage because at 14 carat useful alloys can be made at all values of $\mathrm{Ag}^{\prime}$. On the 14 carat section in Figure 4, although the immiscibility gap is well developed, there is a substantial homogeneity temperature range between the top of the gap and the solidus. This permits alloys at all values of $\mathrm{Ag}^{\prime}$ to be homogenised at elevated temperature and to be quenched as homogeneous solid solutions at room temperature. In this quenched or solid solution condition, the hardness varies with $\mathrm{Ag}^{\prime}$, being lowest for type I alloys, increasing rapidly throughout the $\mathrm{Ag}^{\prime}$ range of type II alloys, and is high in type III alloys. Silver-rich type I and II alloys are somewhat softer than copper-rich type I and II alloys.

Workability is essentially related to the hardness range. Type I alloys are the most easily worked. However, they are not hardenable except by coldworking. Type II alloys are more versatile. They are workable in the annealed state and can be precipitation hardened after fabrication. In special cases where maximum hardness is required (gold pen nibs for instance), type III alloys are available. These alloys are complex to process. They are the hardest and most difficult to work. They require careful quenching, and if not quenched rapidly and effectively, decomposition and resulting hardening will occur.

Examples of 14 carat alloy compositions are given in Table I. Most of the compositions discussed here are commercial alloys that have been, or are currently popular in North America. The particular compositions used in various parts of the world depend to a large extent on local hall-marking laws and colour preferences. Proprietary names have been avoided and the alloys in Table I are designated by code numbers and arranged in order of increasing $\mathrm{Ag}^{\prime}$ and zinc content. These two factors together with caratage largely specify the metallurgical nature of each alloy. Table II lists Rockwell superficial hardness values (HR45T) in the annealed and heat treated conditions. The values were determined on wrought samples $63 \times 13 \mathrm{~mm}$, deformed 50 per cent by cold-rolling to $0.8 \mathrm{~mm}$ gauge. All samples were annealed at $650^{\circ} \mathrm{C}$ for 30 minutes. This treatment led to standard reference conditions for all the alloys, from which comparative hardenability studies were undertaken.

It should be emphasized at this stage that in shop production, it is usually necessary to select the anneal- ing schedule best suited to each particular alloy. For example, annealing at $650^{\circ} \mathrm{C}$ is sufficient to both recrystallise and homogenize all of the alloys under discussion. In practice, however, with wrought material, one needs to steer clear of both the Scylla and Charybdis of gold jewellery annealing for subsequent forming - the directionality of properties associated with under-annealing, and the orange peel effects associated with over-annealing. On the other hand, when solution annealing castings for subsequent precipitation hardening where the only objective is to put the alloy into solid solution, one leans in the direction of relatively higher temperatures and longer times. In general, the annealing temperature recommended for shop practice varies with $\mathrm{Ag}^{\prime}$, being lowest for type I alloys, intermediate for type II, and highest for type III.

The hardness values reported in Table II for annealed samples cover the range that can be expected in practice depending on whether or not the alloy is adequately quenched. The lower value in the range can be attained if the alloy is quenched in water. The higher value may result if the alloy is cooled in air: The range of hardness values for type III alloys vividly illustrates the necessity of fast quenching when these alloys are process annealed for subsequent working.

The hardness values after heat treatment reported in Table II were determined on samples solution annealed at $650^{\circ} \mathrm{C}$ for 30 minutes and water quenched prior to hardening at the indicated temperature for 2 to 4 hours.

The hardness values after annealing and water quenching and the maximum hardness values after heat treatment which are listed in Table II have been plotted against $\mathrm{Ag}^{\prime}$ in Figure 6. A comparison of this plot with the 14 carat section in Figure 4, shows how well the concept of $\mathrm{Ag}^{\prime}$ imposes order on 14 carat jewellery gold alloys. The relationship between composition, hardening characteristics, and the phase structure of the alloy system is quite symmetrical. The relationship is further illustrated in Figure 7, which shows the metallographic structures of the series of alloys coded 110 to 840 (see Table I). These structures were developed by annealing at $650^{\circ} \mathrm{C}$ for 1 hour and slow overnight cooling in the furnace. Water quenched samples of the same alloys all had homogeneous solid solution structures. The varying amount of precipitation and decomposition which can take place as compositions shift across the immiscibility field from the copper side to the silver side with increasing $\mathrm{Ag}^{\prime}$ is clearly evident.

Comparing the hardness values of alloy 110 (11 per cent $\mathrm{Ag}^{\prime}, 0.2$ per cent zinc) in the quenched and the hardened conditions with those of alloy 116 (11 per cent $\mathrm{Ag}^{\prime}, 6.4$ per cent zinc) and the values of alloy 220 
Table 1

Compositon of Some 14, Carat Gold Alloys Commonly Used for Jewellery Manufacture in North America

\begin{tabular}{|c|c|c|c|c|c|c|}
\hline \multirow{2}{*}{$\begin{array}{l}\text { Alloy } \\
\text { code }\end{array}$} & \multicolumn{4}{|c|}{ Composition, wt. per cent } & \multirow{2}{*}{$\begin{array}{c}\mathrm{Ag}^{\prime} \\
\text { per cent }\end{array}$} & \multirow{2}{*}{$\begin{array}{l}\text { Alloy } \\
\text { type }\end{array}$} \\
\hline & $\mathrm{Au}$ & $\mathrm{Ag}$ & $\mathrm{Cu}$ & $\mathrm{Zn}$ & & \\
\hline 110 & 58.3 & 4.6 & 36.9 & 0.2 & 11 & 1 \\
\hline 220 & 58.3 & 9.1 & 32.4 & 0.2 & 22 & $\|$ \\
\hline 310 & 58.3 & 12.9 & 28.6 & 0.2 & 31 & III \\
\hline 400 & 58.3 & 16.5 & 25.0 & 0.2 & 40 & 111 \\
\hline 600 & 58.3 & 24.8 & 16.8 & 0.2 & 60 & III \\
\hline 750 & 58.3 & 31.0 & 10.5 & 0.2 & 75 & III \\
\hline 780 & 58.3 & 32.5 & 9.0 & 0.2 & 78 & 11 \\
\hline 850 & 58.3 & 35.0 & 6.5 & 0.2 & 84 & 11 \\
\hline 116 & 58.3 & 4.0 & 31.3 & 6.4 & 11 & 1 \\
\hline 224 & 58.3 & 8.3 & 29.2 & 4.1 & 22 & ॥ \\
\hline
\end{tabular}

Table II

Rockwell Superficial Hardness (HR45T) of Some 14 Carat Coloured Gold Alloys in the as Annealed and Precipitation Hardened Conditions

\begin{tabular}{|c|c|c|c|c|}
\hline \multirow{3}{*}{$\begin{array}{l}\text { Alloy } \\
\text { code }\end{array}$} & \multirow{3}{*}{$\begin{array}{l}\text { Annealed } \\
\text { condition } \\
\text { HR45T }\end{array}$} & \multicolumn{3}{|c|}{$\begin{array}{l}\text { Hardened condition after annealing and quenching } \\
\text { HR45T }\end{array}$} \\
\hline & & \multicolumn{3}{|c|}{ Hardening temperature } \\
\hline & & $205^{\circ} \mathrm{C}$ & $260^{\circ} \mathrm{C}$ & $315^{\circ} \mathrm{C}$ \\
\hline 110 & 38.40 & $42-48$ & $45-46$ & $42-43$ \\
\hline 220 & $47-51$ & $68-69$ & $75-76$ & $75-76$ \\
\hline 310 & $53-63$ & $73-74$ & $75-76$ & $75-76$ \\
\hline 400 & $58-7.1$ & $70-74$ & $71-73$ & $74-75$ \\
\hline 600 & $58-69$ & $70-71$ & $71-72$ & $74-75$ \\
\hline 750 & $49-68$ & & $68-69$ & $71-72$ \\
\hline 790 & $43-53$ & & $65-66$ & $68-69$ \\
\hline 850 & $34-38$ & & $60-62$ & $64-65$ \\
\hline 116 & $25-28$ & $32-33$ & $27-28$ & $33-36$ \\
\hline 224 & $40-43$ & $65-67$ & $71-72$ & $60-61$ \\
\hline
\end{tabular}

Specimens: $50 \times 13 \times 0.8 \mathrm{~mm}$, cold rolled 50 per cent prior to annealing. Annealing time and temperature: 30 minutes at $650^{\circ} \mathrm{C}$. Hardening time: 2 to 4 hours

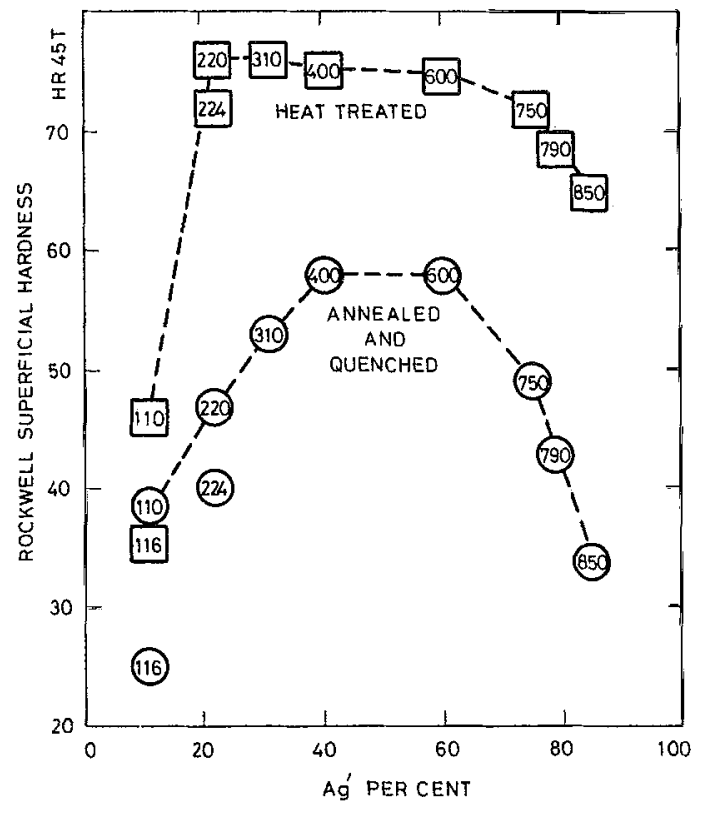

(22 per cent $\mathrm{Ag}^{\prime}, 0.2$ per cent zinc) with those of alloy 224 (22 per cent $\mathrm{Ag}^{\prime}, 4.2$ per cent zinc) in Table II and Figure 6, illustrates the softening effect of zinc additions which was previously referred to.

\section{Carat Coloured Alloys}

A comparison of the 10 and 14 carat sections in Figure 4 shows a broader and higher immiscibility field at 10 carat. A 14 carat alloy with a particular value of $\mathrm{Ag}^{\prime}$ can be converted into its 'associate' 10 carat alloy by reducing the gold content while maintaining the same relative proportion of other alloying elements and thus maintaining the same value of $\mathrm{Ag}^{\prime}$.

Fig. 6 Rockwell superficial hardness (HR45T) of 14 carat commercial gold alloys in the annealed and quenched and the heat treated conditions as a function of $\mathrm{Ag}^{*}$. The alloys are coded as in Tables I and II 


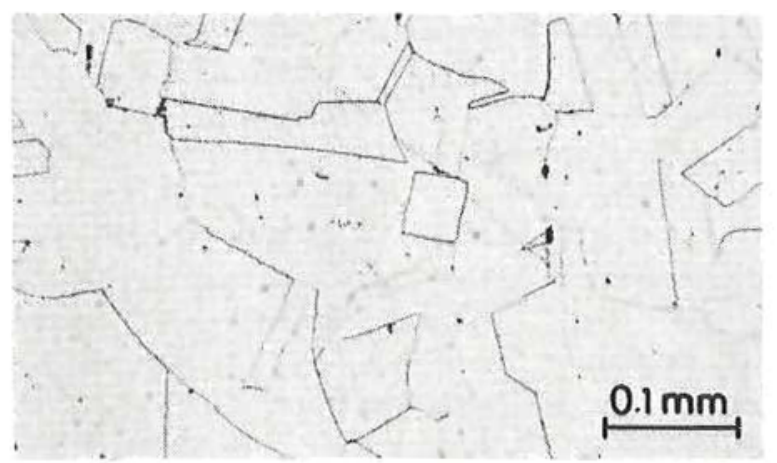

A) Alloy $110, \mathrm{Ag}^{\prime}=11 \%$, type I

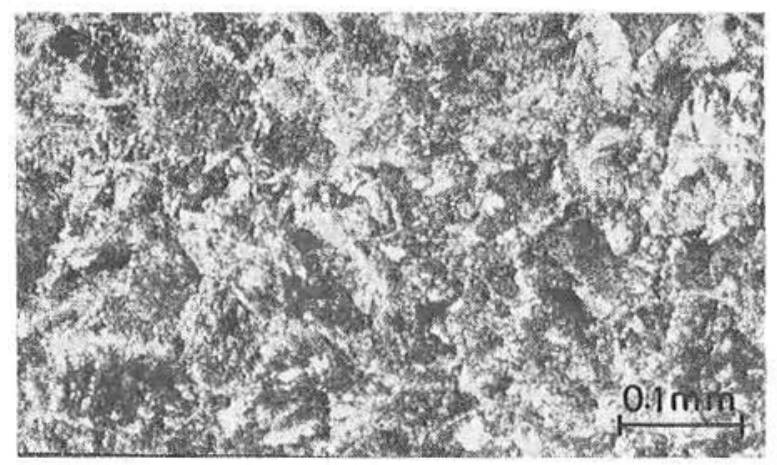

C) Alloy $310, \mathrm{Ag}^{\prime}=31 \%$, type III

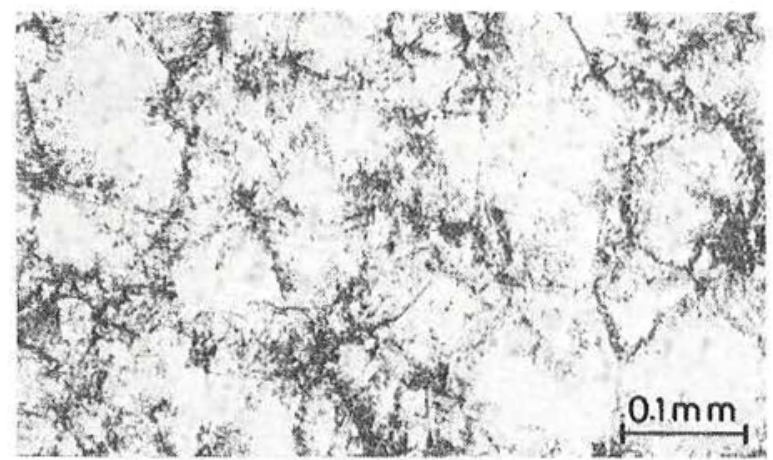

E) Alloy $600, \mathrm{Ag}^{\prime}=60 \%$, type III

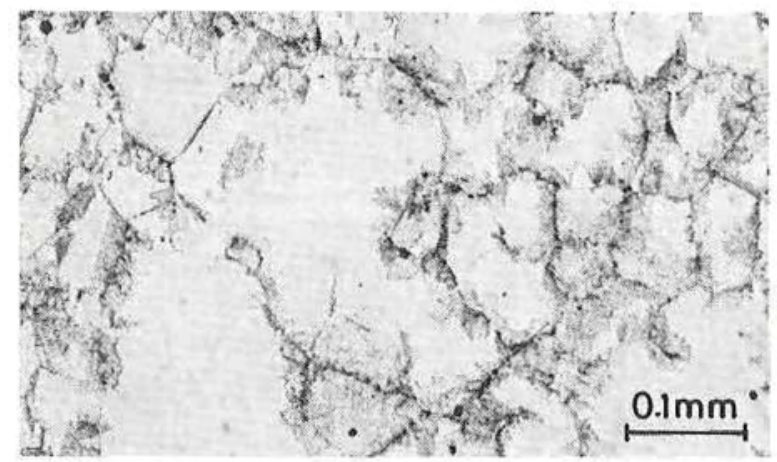

G) Alloy 780, Ag' $=78 \%$, type II

Fig. 7 Equilibrium mierostructures developed in 14 carat alloys 110 to 850 (see Table $\mathrm{I}$ ) by annealing at $6500^{\circ} \mathrm{C}$ for 1 hour and slow overnight cooling:

A: Homogeneous copper-rich solid solution

B: Homogeneous copper-rich solid solution with silver-rich second phase precipitates at the grain boundaries

C. and D: Immiscible coppern-rich and silver-ricli phases.

E to H: Homogeneous silver-rich solid solution with copper-rich second phase precipitates at the grain boundaries

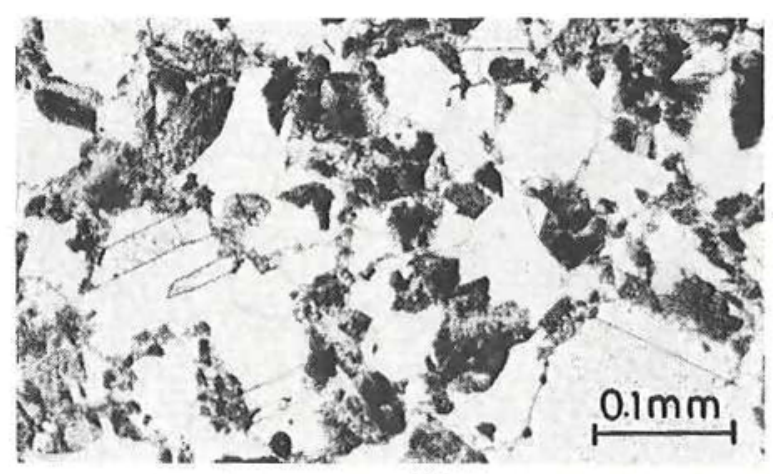

B) Alloy $220, \mathrm{Ag}^{\prime}=22 \%$, type II

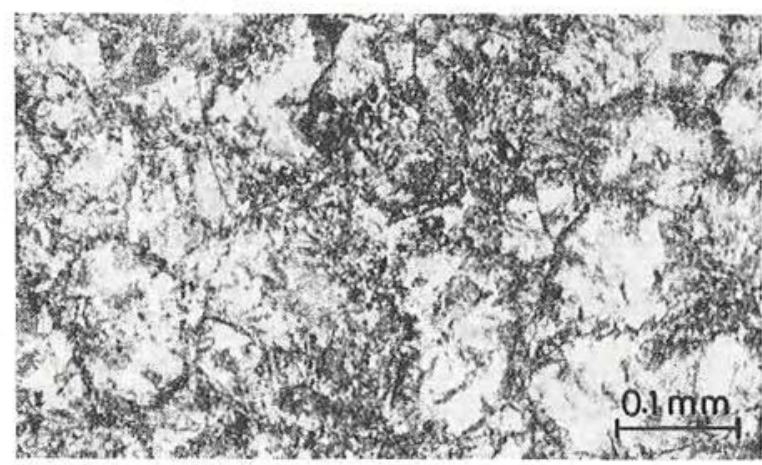

D) Alloy $400, \mathrm{Ag}^{\prime}=40 \%$, type III

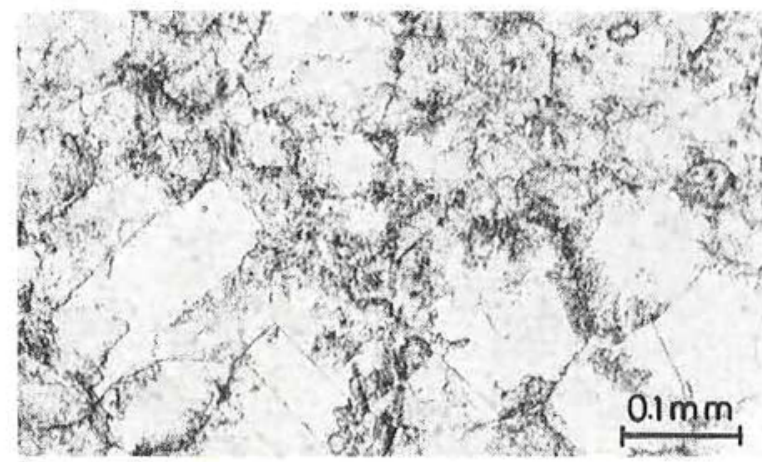

F) Alloy $750, \mathrm{Ag}^{\prime}=75 \%$, type III

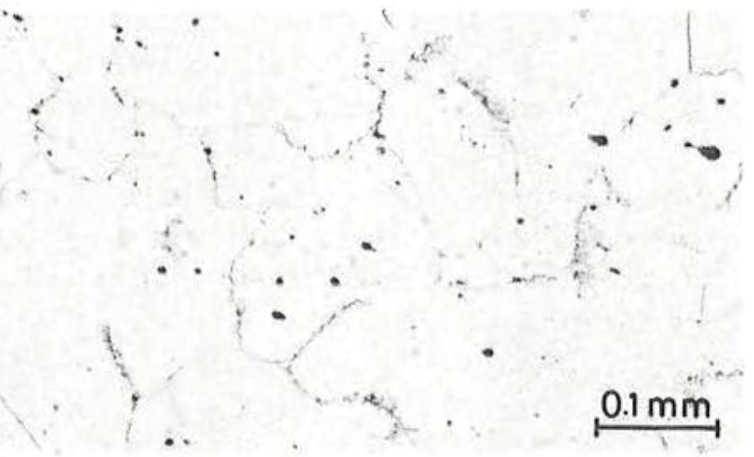

H) Alloy 850, $\mathrm{Ag}^{\prime}=84 \%$, type II
110 to 850 (see Table $\mathrm{I}$ ) by annealing at $650^{\circ} \mathrm{C}$ for 1 hour 
Under these conditions, an alloy of a given type (in the sense defined earlier) at 14 carat will generally convert to an alloy of the same type at 10 carat. However, in some cases the properties of an alloy converted from 14 to 10 carat may be significantly altered, depending on the particular value of $\mathrm{Ag}^{\prime}=$ It can be seen how this takes place by considering Figure 3 and imagining lines dropped from the gold corner to particular values of $\mathrm{Ag}^{\prime}$ on the silver-copper base. All 'associated' alloy compositions falling on a particular line have the same value of $\mathrm{Ag}^{\prime}$. If such a line falls outside the immiscibility field at 14 and 10 carat, the properties of the associated alloys will be very similar at both caratages. They will be relatively soft homogeneous solid solutions and not precipitation hardenable. This is the case for type I alloys. If the constant $\mathrm{Ag}^{\prime}$ line falls inside the immiscibility field at both caratages, it is always the case that it is farther inside the field at 10 carat than at 14 carat because the immiscibility field is broader at 10 carat than at 14 carat. How this effects changes in properties depends on the range of $\mathrm{Ag}^{\prime}$. Type III alloys, which are well inside the immiscibility field at both caratages tend to have similar properties at 10 and 14 carat. However, at 10 carat they are much harder and much more difficult to anneal and quench than at 14 carat. Marked differences can occur in the conversion of type II alloys. In this range, a yellowish alloy or a greenish alloy 'just inside' the immiscibility field at 14. carat and capable of only moderate precipitation hardening may, on conversion to 10 carat be "well inside' the field and precipitation harden to a significant degree. Such displacements relative to the immiscibility field will also affect the process annealing, solution annealing and optimum precipitation hardening temperature, optimum ageing time, and susceptibility to overageing and softening. Alloy additions of zinc also have an effect in changing properties on converting between 14 and 10 carat because zinc tends to reduce the volume of the immiscibility field, and the absolute zinc content increases with conversions which maintain the same relative proportions of the alloying elements (silver, copper, and zinc).

At 10 carat, type III alloys are not in general use because they are too hard and difficult to anneal for practical fabrication and their colour is not attractive.

The compositions (weight per cent) of three typical commercial 10 carat jewellery gold alloys are listed below:

$\begin{array}{ccccccc}\text { Code } & \mathrm{Au} & \mathrm{Ag} & \mathrm{Cu} & \mathrm{Zn} & \mathrm{Ag}^{\prime} \% & \text { Type } \\ 119 & 41.7 & 5.50 & 43.8 & 9.0 & 11 & \text { I } \\ 226 & 41.7 & 11.70 & 40.8 & 5.8 & 22 & \text { II } \\ 840 & 41.7 & 48.90 & 9.05 & 0.35 & 84 & \text { II }\end{array}$

These alloys are based on the conversion of 14 carat alloys 116, 224, and 850 listed in Table I and have been arrived at as described above. The type I alloys (14 carat 116 and 10 carat 119) have mechanical properties so nearly the same at both caratages that they can be processed in essentially the same way. The type II yellow alloys (14 carat 224 and 10 carat 226) show significant differences between the two caratages. For example, 224 is solution annealed in 30 minutes at $650^{\circ} \mathrm{C}$ whereas 30 minutes at $705^{\circ} \mathrm{C}$ are required with 226 . The optimum precipitation hardening schedule for 224 is ageing between 230 and $260^{\circ} \mathrm{C}$ for 2 to 4 hours, while 226 is aged at $315^{\circ} \mathrm{C}$ for 1 hour. Heat treatment of the 14 carat alloy at $315^{\circ} \mathrm{C}$ will result in overageing and softening while if the 10 carat alloy is treated at $260^{\circ} \mathrm{C}$ maximum hardness will not be obtained.

The maximum hardness of the two alloys after heat treatment is about $71 \mathrm{HR} 45 \mathrm{~T}$ for 224 and $73 \mathrm{HR} 45 \mathrm{~T}$ for 226 . These differences are due primarily to the relative displacement of the solid solution boundary from the $\mathrm{Ag}^{\prime}=22$ per cent line to the left in converting from 14 to 10 carat. However, alloy 224 which contains 4 per cent zinc converts into 226 with 6 per cent zinc. The additional 2 per cent of zinc at 10 carat shifts the solid solution boundary back to the right and therefore reduces the net displacements. The type II green alloys ( 14 carat 850 and 10 carat 840 ) also exhibit some interesting differences in properties. Again, the 14 carat alloy can be solution annealed at $650^{\circ} \mathrm{C}$ for 30 minutes, but with the 10 carat alloy $705^{\circ} \mathrm{C}$ for 30 minutes is required. Both can be precipitation hardened at $315^{\circ} \mathrm{C}-850$ in 2 hours and 840 in 2 to 4 hours. The maximum hardness of the 14 carat alloy in the heat treated condition is 65 HR45T, while it is $70 \mathrm{HR} 45 \mathrm{~T}$ for the 10 carat alloy. The latter is so much further into the two phase region than the 14 carat alloy that it acquires one of the characteristics of type III alloys, namely, it is very susceptible to hardening on air cooling and must be effectively quenched on annealing if subsequent forming operations are intended.

\section{Carat Coloured Alloys}

On the 18 carat section in Figure 4 it will be noted that the immiscibility field occupies a much smaller area of the solid state field than at lower caratage. Also, the $\mathrm{AuCu}$ ordered phase of the gold-copper binary system intrudes into the ternary field. The concept of alloy types used above in discussing 10 and 14 carat alloys is far less useful at 18 carat. For example, a copper-rich alloy in the $\mathrm{Ag}^{\prime}$ range corresponding to type I, which would be non age-hardenable and soft at 10 and 14 carat, is hardenable at 18 carat due to the effect of the AuCu ordered phase. Alloys in the $\mathrm{Ag}^{\prime}$ range corresponding to type III, which are all hard at 10 and 14 carat, are only moderately hard and age-hardenable at 18 carat due to the restricted area of 
the immiscibility field, and behave more like type II alloys do at 10 and 14 carat. Soft and non agehardenable alloys are found in the range of $\mathrm{Ag}^{\prime}$ greater than about 75 per cent. Above 18 carat, the concept of type is not practically useful at all. In this range, the alloys both annealed and heat treated are progressively softer with increasing gold content and approach the properties of 24 carat or pure gold.

If one refers to the colour diagram in Figure 5, and imagines lines drawn from the gold corner through the intersection of the colour boundaries with the 18 carat line and then continued to the $\mathrm{Ag}^{\prime}$ values on the silver-copper axis it can be seen that at 18 carat, red gold alloys occur in the $\mathrm{Ag}^{\prime}$ range 0 to about 40 per cent, yellow alloys in the $\mathrm{Ag}^{\prime}$ range 40 to 80 per cent, and green alloys in the $\mathrm{Ag}^{\prime}$ range from about 80 to 100 per cent. If one now observes where these ranges fall on the 18 carat quasi-binary section in Figure 4, the following generalisations can be made:

All 18 carat green alloys behave like type I soft and non-precipitation hardenable alloys because their compositions fall well outside the immiscibility field. There are no type I red alloys at 18 carat because at low values of $\mathrm{Ag}^{\prime}$ the ordering of the $\mathrm{AuCu}$ phase is available as a hardening mechanism. Yellow alloys at
18 carat fall within the $\mathrm{Ag}^{\prime}$ range of type III alloys at 10 and 14 carat, but behave like 14 carat type II alloys do as indicated above.

The compositions (weight per cent) of three typical 18 carat jewellery alloys are listed below:

$\begin{array}{lccrcc}\text { Colour } & \text { Code } & \mathrm{Au} & \mathrm{Ag} & \mathrm{Cu} & \mathrm{Ag}^{\prime} \% \\ \text { Red } & 200 & 75 & 5 & 20 & 20 \\ \text { Yellow } & 600 & 75 & 15 & 10 & 60 \\ \text { Green } & 900 & 75 & 23 & 2 & 90\end{array}$

The red alloy 200 responds to hardening on heat treating (75 HR45T after solution annealing at $595^{\circ} \mathrm{C}$ followed by hardening at $260^{\circ} \mathrm{C}$ for 2 hours), although its position at 20 per cent $\mathrm{Ag}^{\prime}$ in the 18 carat section of Figure 4 suggests that it might fall outside the influence of both the ordered field and the immiscibility gap. The yellow alloy 600 can be treated to $66 \mathrm{HR} 45 \mathrm{~T}$ by solution annealing at $650^{\circ} \mathrm{C}$ followed by precipitation hardening at $260^{\circ} \mathrm{C}$ for 2 hours. The green alloy 900 is not precipitation hardenable.

\section{References}

1 'Metals Handbook', 8th edition, vol. 8, American Society for Metals, Metals Park, Ohio, 1973

2]. Leuser, Metall, 1949, 3, 105-110, 128

3 C. McCaul, R. Krahn and C. d'Antonio, Trans. Am. Inst. Min. Metall. Eng., 1969, 245, 432-434

The second part of this article will be published in the October 1978 issue of Gold Bulletin.

\section{The Thermal Conductivity of Gold}

In low temperature equipment, thermal contact between solid state devices, thermometers etc. and the surroundings may be limited by the conductance of thin gold wires between them. Prediction of the thermal conductivity of such wires at low temperatures is therefore of importance. As a result of measurements reported by V. Novotny from the Department of Physics at the University of Toronto (1), such prediction is now possible.

The conduction of heat in gold is due almost exclusively to electrons, since phonons are effectively scattered. This means that the two conduction processes electrical and thermal, are very similar. In fact there exists a very simple relationship between the two, the Wiedemann-Franz (WF) law, established over a hundred years ago. This is$$
\lambda / \sigma \mathrm{T}=\mathrm{L}_{0}
$$

where $\lambda$ is the thermal conductivity

$\sigma \quad$ is the electrical conductivity

$\mathrm{T}$ is the absolute temperature in degrees $\mathrm{K}$
}

and $L_{0}$ is the Lorenz number, which is a constant of value $2.45 \times 10^{8} \mathrm{~W} \Omega / \mathrm{K}^{2}$. Since the electrical conductivity is much easier to measure, one may derive the thermal conductivity of a metal from the above equation, provided that no deviations from the WF law occur.

The WF law has been established, however, on the basis of elastic scattering. Although this is a good approximation for gold at temperatures below $10 \mathrm{~K}$ and above $300 \mathrm{~K}$, between these temperatures the ratio $\lambda / \sigma \mathrm{T}$ decreases, depending on sample purity. In pure metals, deviation arises from non-elastic electron-phonon scattering processes which generally show up between $\theta_{\mathrm{D}}$ (the Debye temperature, which for gold is about $190 \mathrm{~K})$ and $\theta_{\mathrm{p}} / 30$. In impure metals, deviation arises from the presence of minute amounts $(\sim 10 \mathrm{ppm})$ of magnetic impurties (iron, chromium, manganese).

Since at very low temperatures the electrical conductivity of pure metals is constant ('residual resistivity'), the thermal conductivity should be proportional to temperature. This is actually observed, with $\lambda=\alpha \mathrm{T}$ where $\alpha=\sigma \mathrm{TL}_{0}$. Where deviations due to the failure of the WF law occur, this relationship does not hold, and the thermal conductivity at low temperature can be written as

$$
\lambda=\alpha \mathrm{T}+\beta \mathrm{T}^{2}+\gamma \mathrm{T}^{3}+
$$

where $\beta$ and $\gamma$ are small.

Commercial gold wires are normally made from high purity gold, and Novotny found for the sample (diameter $51 \pm 1 \mu \mathrm{m} ; 99.7$ per cent gold) studied by him that the thermal conductivity was given by

$$
\lambda=0.117 \mathrm{~T}+7 \times 10^{-4} \mathrm{~T}^{2} \quad\left(\mathrm{WK}^{-1} \mathrm{~cm}^{-1}\right)
$$

between 0.8 and $10 \mathrm{~K}$.

The data agree within 20 per cent with those calculated from the measured residual electrical resistivity using the WF law. This implies that predictions of the thermal conductivity of other gold wires at low temperatures can be made to within engineering accuracy over a wide range of residual resistance ratios.

Reference

J.K.

1 V. Novotny, Cryogenics, 1977, 17, 451-452 